Simon O'Sullivan

\title{
Myth-Science and the Fictioning of Reality
}

In what follows I put forward an idea of contemporary art practice as a form of myth-science, itself defined as a kind of fictioning of reality. ${ }^{1}$ Most of what follows has been developed in relation to the collaborative 'performance fiction' Plastique Fantastique (and especially in conversation with David Burrows) and thus, in acknowledgement of this parallel research programme, interspersed throughout the text are images from our practice and, in particular, a performance itself titled 'Myth-Science'. ${ }^{2}$ I hope that this local 'scene' might resonate on a more global level, but also that my comments will not be read as being solely tethered to this particular collaboration (indeed, my article intends the mapping of a more general trajectory in art). The article ends with a brief Coda on Felix Guattari's concept - from Schizoanalytic Cartographies - of 'fabulous images' that offers another inflection on my theme.

...theres some thing in us it dont have no name...it aint us but yet its in us...

(Russell Hoban, Riddly Walker)

\section{Introduction: Art and the World (or, that which is in the world but not of the world)}

When art engages directly with the world as-it-is it already surrenders some of its power. It has to use more or less recognizable forms, languages, narratives - even if these are idiosyncratic and/or marginal in nature. Another way of saying this is that such art is both of and for the world in which it is situated - or, which amounts to the same thing, it already has its audience in place. Jean-François Lyotard says as much in his claim that art can simply 'multiply the fantasies of realism' rather than, precisely, disrupting them (which, in Lyotard's view, is art's true avant-garde function) (Lyotard 1984, 74). Another way of putting this is that art does not necessarily offer a reassuring image of and to a subjectivity already in place (although it may of course operate in this manner).

1 The article draws on and develops ideas first put forward in O'Sullivan 2014. The term mythscience is borrowed from Sun Ra and Afrofuturism more generally (see Kodwo Eshun's discussion, "Synthesizing the Omniverse", in Eshun 1998, 154-163). The artist Mike Kelley, in an essay on Olaf Fahlstrom (Kelley 1995), links the term more particularly to expanded contemporary art practice.

2 "Myth-Science" was performed in 2014 at the "Webewoche" exhibition/event, Stroom den Haag, The Hague and at the "Schizo-Culture" exhibition/event, Space Gallery, London (see http://www. plastiquefantastique.org/performance25.html). Plastique Fantastique, for this performance, involved myself and Burrows alongside Alex Marzeta and Harriet Skully. 


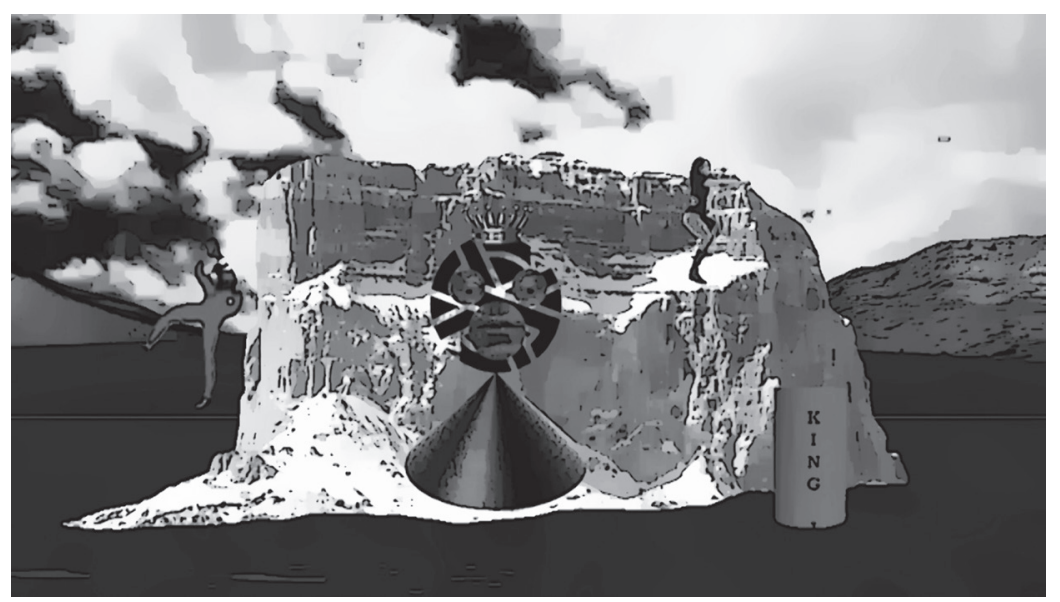

In its engaged and oppositional form - institutional critique, for example - such art is still about the world. Indeed, the more engaged it is, the more it must mirror, however critically (or negatively), its object. Such critique, again as Lyotard once remarked, is trapped by its target, towards which it must, to some extent, adjust itself in order to engage. This kind of 'critical' art practice can operate as a kind of melancholic echo chamber in this sense (we might say that this is also the limitation of understanding art more generally as a form of ideology critique).

The so-called 'archival turn' within contemporary art would be a softer example of this logic. Here, art practice becomes an archiving gesture, a framing and presenting of a subset of the world. An archive practice is first and foremost curatorial in this sense; it gathers together hitherto separate elements under a banner (a concept, a theme, a name, and so on), but, crucially, it does not necessarily transform these elements. Indeed, ultimately it offers nothing more than a product (or a series of products) designed to meet the desire for knowledge - when the latter is understood as knowledge of the world as-it-is.

As has often been pointed out, the 'Art World' is insatiable in this respect; it requires evermore banners just as it creates ever more artist-archivist-curators (or, simply, new products and new consumers). Novelty here consists of new groupings of the what-already-is, the trumping of one set of knowledges with another, the identification of counter or dissonant knowledges (that nevertheless operate on the same register of typical 'meaning'). Indeed, knowledge becomes the currency of such practices (knowledge is power as the saying goes - at least power of a worldly kind).

On the other hand, can art ever be anything but the presentation of a subset of the world, seeing as it is a practice that takes place in that very world? Here, the definition of a world - what it includes and what it excludes - is crucial insofar as we might make the tentative claim that art can be specifically other-worldly without meaning it is somehow outside the world as-it-is (indeed, how could it be?). In fact, an art 
practice that attempts to operate completely divorced from the world - understood here as our dominant contemporary conditions - runs the risk of irrelevance, escapism or simply being a sophisticated form of withdrawal.

Nevertheless, it is certainly the case that art's 'materials' are not simply of the world as constituted. As such, it follows that its audience - an audience adequate and appropriate to it - is not always already in place. Art, in this sense, can be understood as untimely, or as in time, but also out of time. It is, as it were, future-orientated. Gilles Deleuze's writings on art foreground this strange temporality of art - that "its people are missing" (Deleuze 1989, 208-211), or, more prophetically, yet-to-come. Art draws something forth from already existing subjectivities in this sense.

But how might this untimeliness manifest itself? What form might it take? One thing is clear: it will not be easy to understand. If it is a communication, it will be one without meaning (to paraphrase Lyotard once more), when meaning is understood as a register of knowledge - or, to introduce another term, as part of the code of the world as-it-is. Hence the important idea that something might be of the world but not of the (dominant) code of that world (might, in this sense, be occult). This might mean that such practices - that communicate without meaning - are not taken seriously or simply frustrate, bore, annoy or irritate. At an extreme they will be imperceptible, at least, according to dominant regimes (and codes) of visuality (hence the importance of learning to see, or, which amounts to the same thing, of attending to our own particular production of subjectivity). It is the edges of our 'understanding' that are important in this sense - this is where everything happens.

The importance of these kinds of practices is then that they offer something different to the what-already-is. This might be simply a diversion - or, at any rate, dismissed as one, as not part of the dominant code (or, apparently, a threat to it), hence, ultimately unimportant. But in other cases, and for different subjects, they are points of inspiration and radical difference that might then be developed and mobilized into a different way of being in the world (and with this foreshadow a different community yet-to-come). Here an art practice presents something more germinal than parasitic. It can be the seed of something genuinely new. In an increasingly homogenized and homogenizing neoliberal present that offers only more of the same - a present that overcodes all options - these points of difference can themselves become politically charged. Indeed, when the political scene offers no new models, art steps up. Here, in fact, it might be less a case of already worked out models than experimental probes, affective scenes, proto-subjectivities, and such like. Art can generate the feel of something different in this sense.

But to construct a genuinely new form of coding one needs material, hence, also in this task, the importance of the scrambling of already-existing code or the importing of more alien code from elsewhere (outside of typical art-world culture) ... at least as a first step. This is a mixing that is both spatial and temporal in nature (more on this in a moment). Ultimately an art practice can then take off from this hybridity and begin to work on its own terms, producing its own (autonomous) coding. For example, it might throw up images or forms that seem to come from a 'somewhere else', 
but that also have some kind of strange relevance to the world as-it-is. Untimely images. It might also begin to recycle and re-use its own motifs, nesting one set of fictions within another, so as to produce a certain complexity - a density even. The idea that a practice might involve moves in a game for which one does not know the exact rules echoes this logic of strangeness and autopoietic functioning.

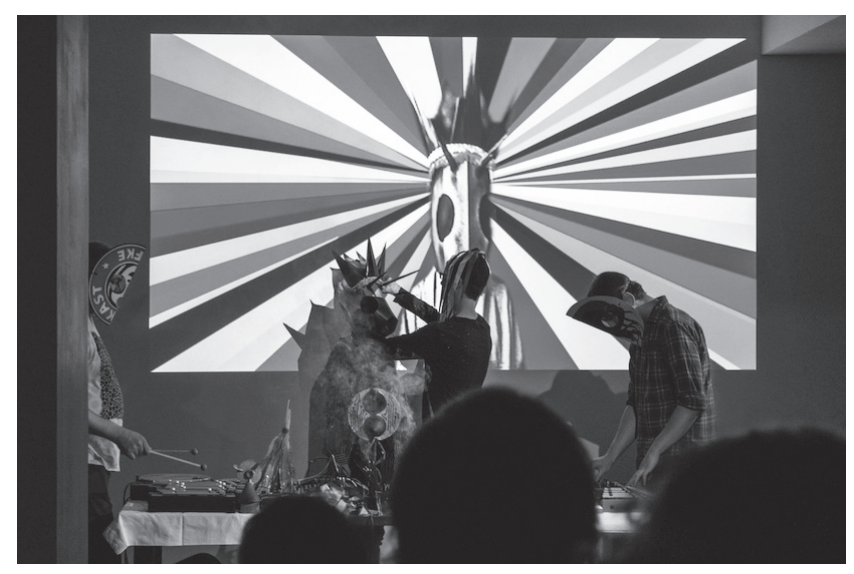

\section{Fictioning: Synchronic and Diachronic Operations (or, speaking back and speaking in tongues)}

One way of articulating this particular logic of art practice is as a 'fictioning': the production of untimely images - that speak back to their producer (1); and the layering of motifs to produce an accretion of sorts, resulting in an opacity (2).

(1) As far as the first of these goes, it might be that a practice just presents the result: the final image (or images). Here the relative strangeness of the image (its difference to the what-already-is) is foregrounded. On the other hand, it might lay out the procedure and protocols that allow this image to step forth from its dark background. Indeed, it might be that a practice stages this event, or even that practice is a name for it (and it is in this last sense that art practice is a very particular type of research programme). Performance can involve what we might call this magical function: the summoning forth of something hitherto unknown and unseen. Collaboration, or more specifically, collectivity - a scene of some kind - is also crucial for this operation. How else can one make something that is of one but not of one at the same time? That is intended but produces the unintended? For ' $\mathrm{I}$ ' is indeed a stranger, but it is only through a specific practice that this stranger can foreground itself from the habitual and familiar. It should be pointed out here that collectivity (again, a scene) need not involve more than a single individual. As Deleuze and 
Guattari remark at the beginning of $A$ Thousand Plateaus, we are always already more than one. ${ }^{3}$

Art speaks back in this sense. It is both cleverer and dumber than its progenitors. This is not to evacuate the subject from the picture. Indeed, such art - like all art - is made for subjects (images and objects made 'for' other images and objects may be many things, but art is not one of them - although I will suggest a caveat to this point in a moment). Nevertheless there is something about this fictioning - this production of something non-subject - that is specifically object-orientated, to use the current valence. It is as if the goal here is to extract a certain objectness (something nonhuman) from an all-too-human subject.

This is the synchronic aspect of fictioning.

(2) In terms of the second aspect, time itself becomes a material insofar as the accretion happens through time, across a work, or across multiple works. It might be that this passage is imperceptible, only able to be tracked by the recurrence of the motifs - or (in Plastique Fantastique's case) avatars - that appear, disappear then reappear (perhaps in a different form), each with their own operating logics, their own speeds (and slownesses). An art practice has a certain duration in this sense - or even multiple durations. A kind of aesthetic ecology is produced which means the practice has more in common with a series, or again, a scene, than with an object per se.

The elements of an art practice can travel in this sense. Fragments of previous codes (and characters) make a re-entry, spliced with other more recent experiments. Such work is a palimpsest even when it looks relatively simple. Another way of articulating this logic is that a practice nests its own fictions within itself. This kind of temporal density comes from the fact that any given moment - any given image of the practice that we see - is an extraction from a process, even a narrative (at least of a kind), that goes from the depths of the past of the work towards a future that the work itself helps to bring about (a practice can be a backward-hurled fragment of a future world in this sense).

This is the diachronic aspect of fictioning.

Art is simple but complex in this sense. It inserts itself into a variety of registers (signifying and asignifying) but it also refers to itself (it is, as it were, inward looking). Or, more accurately, it works on itself ... follows lines of enquiry, repeats certain moments, accelerates some motifs ... slows others down ... in so doing, art itself constitutes a world - its own world (as well as the terms in which it may be 'understood'). And this, ultimately, is its power.

3 "The two of us wrote Anti-Oedipus together. Since each of us were several, there was already quite a crowd" (Deleuze/Guattari 1988, 1). 


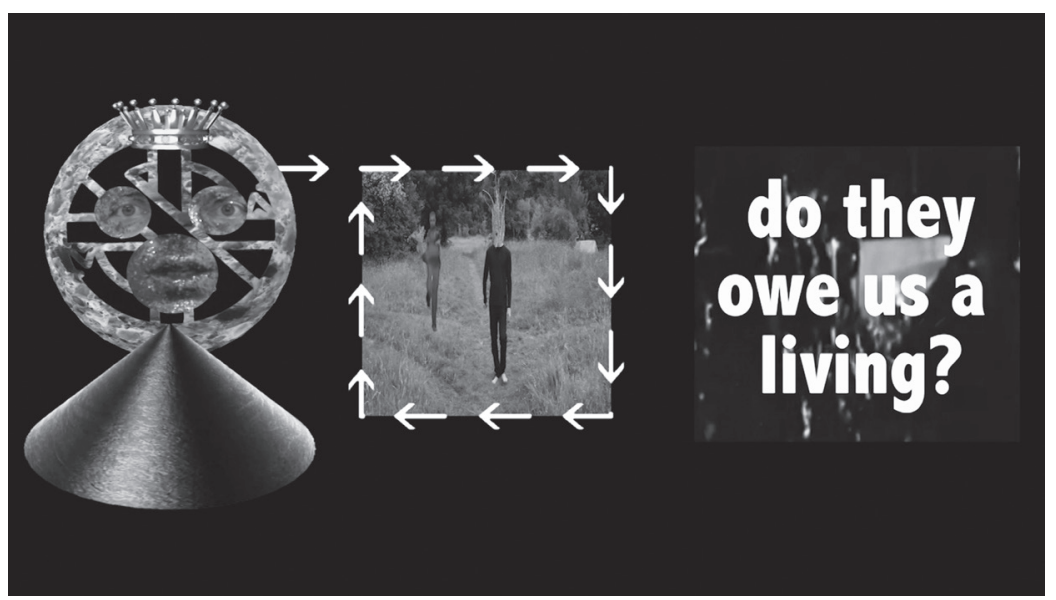

\section{From Collapsing Worlds to Points of Collapse (or, a holding pattern of minimum consistency)}

In a way, both of the above modes of fictioning involve a layering. Again, the first is spatial, the second temporal. It is this spatio-temporal density - which results in the production of a different space-time - that constitutes art when it is a practice rather than simply the production of a commodity (the production of untimely images does share with the commodity form a certain magical character - this is a kind of 'counter-sorcery' pitched against the phantasmagoria of the commodity).

The increasing availability and relative affordability of digital imaging and editing technology means that there is now the possibility of a more accelerated mixing of different temporal and spatial worlds and, as such, of increasing this density and, with it, producing ever stranger spatialities and temporalities. Such technology also allows its user to alter the speeds of the different images and sequences being deployed. This might mean the introduction of a different character (or a different speed) into a different scene that has its own duration, or, indeed, the insertion of one scene into another. In this strange dream-time a virtual 'third thing' is introduced between the two. A no-place and a no-time. An 'erewhon' when and where other things become possible. This is also an indirect answer to the ever present 'now' of commodity culture insofar as it often involves recourse to a recent past (alongside its imagined futures) - a line to that which has been too easily and eagerly forgotten in the ever increasing and insatiable desire for the apparently new (it is this recalling of a past in a future-to-come that marks out some of the best recent digital art practices). ${ }^{4}$

This collapsing of hitherto separate worlds - and the concomitant production of a 'new' landscape, a new platform for dreaming - is another definition of fictioning,

4 This is the subject of a further parallel essay-in-progress on "Myth-Science as Residual Culture and Magical Thinking". 
especially when it is no longer clear where the fiction itself ends and so-called reality begins (or where reality ends and the fiction begins). Fictioning inserts itself into the real in this sense - into the world as-it-is (indeed, it collapses the so-called real and the fictional), but, in so doing, it necessarily augments and, indeed, changes our reality (not least as, again, it summons an audience that is appropriate and adequate to it). ${ }^{5}$ This is fictioning as mythopoeisis: the imaginative transformation of the world through fiction.

This particular sense of fictioning dovetails with the idea of post-internet art, or art that is made from and for the web of images that now doubles - and troubles - our own world of things. As such it might be said that the collapsing worlds we produce have their own life outside of our control, or, indeed, anyone else's. Ultimately, they do not rely on being seen to operate as agents (after all, who, nowadays, can see all the images that are generated?). They are already in contact and 'communication' with image-worlds that are increasingly not of human generation. Once again the question here is whether such worlds that operate divorced from any kind of subject can be called art (who, after all, is there to call them anything?). It is perhaps more accurate to say that they become art when confronted by an interlocutor (although this will not necessarily be a 'human' in the sense of a particular historical diagram, with an inside and outside, a centered 'self', and so on. More on this other subject in a moment).

Is art the only place where we find this logic of collapsing worlds? Or, indeed, the spatial and temporal layering I have just laid out? Certainly other aspects of culture utilize the latter, albeit only partially and somewhat reductively. Fashion, for example (as spatial layering), or the mini-series (as a form that involves longer durations than the typical film or, indeed, the novel). In terms of collapsing worlds we need only look at the post-continuity cuts of recent pop videos (but also note that a strange continuity is maintained 'behind' the videos themselves in the 'lives' of the celebrities as narrated on-line and on TV). This amounts to saying that our particular (and, as it were, dominant) world (or let us now give it its other name: capitalism) generates its own experiments outside of art - experiments that in some senses double art's own probe heads.

But in art, the processes that I have just outlined are accentuated beyond the reasonable. Art is like a joke pushed to an extreme in this sense. From a certain perspective it is like an ongoing absurd repetition, a gesture beyond the logics of the market.

5 The concept of 'hyperstition' as developed by Nick Land (and the Cybernetic Culture Research Unit (Ccru)) might be usefully brought to bear here insofar as it likewise points to elements of fiction making themselves real. Alex Williams, co-writer of the "Manifesto for Accelerationist Politics", provides a useful gloss on this in his essay on accelerationist aesthetics in which hyperstition is defined as "narratives able to effectuate their own reality through the workings of feedback loops, generating new sociopolitical attractors" (Williams 2013,9). It seems to me that art practice as fictioning - as I have been defining it - involves both a narrative function (at least of a sort) and 'sociopolitical attractors' (untimely images) generated by the latter, but also generative of them in turn. For more on Land and Ccru's concept of hyperstition (in relation to myth-science) see O’Sullivan 2016b. 
Indeed, art does not have to maintain even a modicum of good/common sense in this respect - or, to say it again, is not necessarily involved in the production of typical knowledge.

Crucially, with art, this often means that something unrecognizable, often accidental, is introduced into the mix. Chances can be taken - after all, there is no audience to please, except for the very specific audience that is looking for something that does not please them (at least, as they are presently constituted). This is the introduction of something random, something that is, as it were, unwelcome and spoils any ready-made and too-neat schema or logic. It is the introduction - or excavation - of rupture, a point of collapse.

In this sense the art practice is not, ultimately, simply the production of subjectivity (at least when this is tethered to dominant regimes of subjectivation). It is not therapeutic, however that might be defined. A practice certainly needs a sense of cohesion, but it also needs these points of collapse - or else it risks just presenting more-of-the-same. I have written about this - with David Burrows - at more length and in relation to Guattari and Jacques Lacan elsewhere (see Burrows/O'Sullivan 2014). Suffice to say here that an art practice might be a kind of holding pattern - maintaining a minimum consistency - for these points of collapse. Indeed, this might, again, be a definition of fictioning: the production of a myth of some kind that binds the holes and presents and pitches them to an audience.

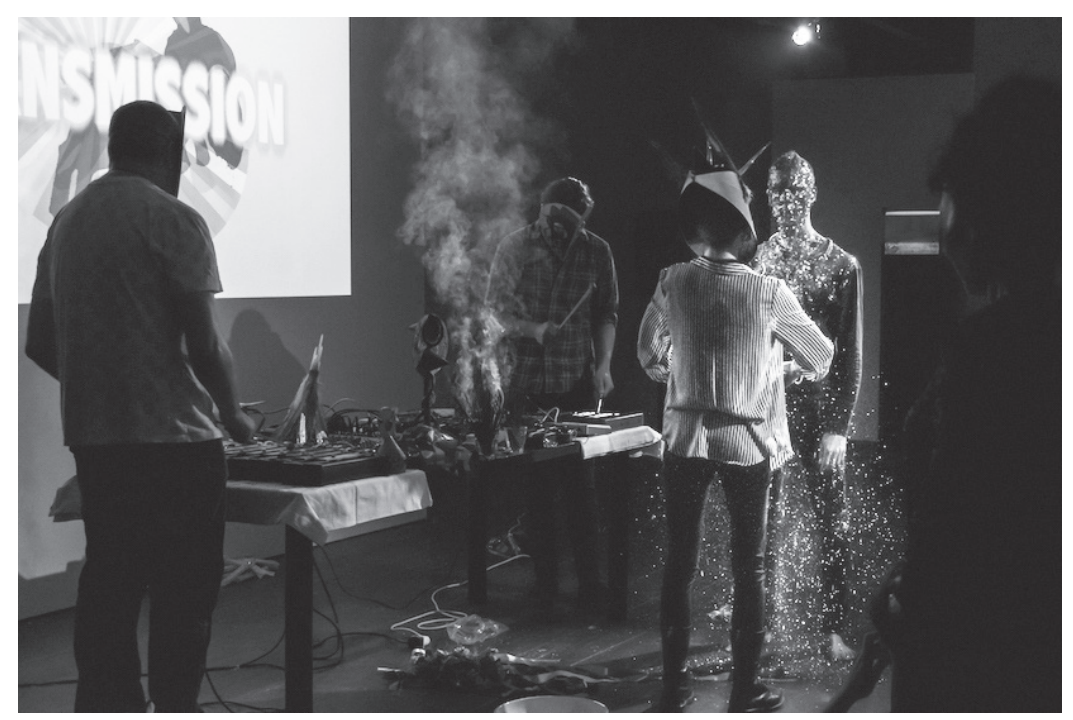




\section{Conclusion: Reclaiming the Unconscious (or, a message not to you but to something 'within' you)}

It is not news to say that Capital has colonized time as well as space, but this needs also to be thought in terms of more imaginary registers, that is to say, not just within reality per se with its typical spaces, places, times and durations, but also in terms of our unconscious worlds. As has also been remarked often enough, the failure of politics is also the failure of the imagination. Capital, we might say, has increasingly co-opted even our dream worlds - that repository of images that give us a life beyond the plane of matter.

Indeed, this unconscious - understood in a Bergsonian sense (as a virtual reservoir that subsists but that is habitually masked by more utilitarian and pragmatic interests) - is being colonized by commodity culture, and not least by Web 2.0 and its logics. Facebook and Twitter and all the other filtering super-nodes of a once wild - and un-enclosed - web offer up a restricted repository of images (and especially interfaces), ever available, seemingly varied, but, in fact, often just more-of-the-same. The result of this is not only a poverty in the sense of the homogenization performed by these image-banks, but also an alienation: we become the spectators of our own subjection insofar as these images and interfaces are not of us, or, at least, are only of a part of us (that part which can be represented by such images and their attendant algorithms). This is not to say that creativity is impossible here. Indeed, as I suggested above, many of the most interesting post-internet practices concern themselves with the digital, and, at the sharp end, the algorithmic. It is to say, precisely, that social media filters our experiences, flattens subjective modellings and, ultimately, is concerned more with markets and consumers than with difference and creativity.

Another way of thinking about the fictioning function of art practice is then as a counter to some of these logics - as the reclaiming and unleashing of this unconscious. Art practice - at least as I have attempted to articulate it here - can produce new images and sequences - new myths and new dream worlds. Again, this is not simply to refuse or resist the existing conditions. In fact, it might well mean plugging in to the productive and generative aspects of capitalism - the deterritorialized flows that are typically and subsequently reterritorialized, siphoned off. Following Deleuze and Guattari's Anti-Oedipus, such art might be said to 'accelerate the process' (Deleuze/Guattari 1984, 240). ${ }^{6}$

An important aspect of fictioning, in this sense, is participation in the fiction. This does not necessarily mean that an audience/spectator is invited into the work - often an artwork is inhospitable (it refuses to give ground). But it does mean that the produced fiction offers something. It is from and for a collectivity (again, even if this is just an individual) - albeit one that is masked by more typical (atomized and hyper-individualized) subjectivity.

6 In terms of the connections - and differences - between these claims for art practice and the Promethean impulse as mapped out by accelerationist writers such as Ray Brassier and Reza Negarestani see O'Sullivan 2017. 
It is also in this sense that this fictioning performs its own alienation: alienation from and for an already alienated subject (indeed, alienation is the given - the very ground - of these practices). Here fictioning's difference from the world as-it-is means it will alienate the subject as-it-is, but, at the same time, speak to the subject yet-to-be. It is a message not to you but to something within you (or, it solicits its own kind of audiences, which amounts to the same thing).

It is also for this reason that difficulty, complexity, the refusal of meaning, and so forth are not always the signs of elitism or a deliberate mystification/obscurification, but the sign of something that will not give ground to the world as-it-is, will not pander to the demand to make sense (at least, following the dominant codes of meaning and top-down decisions about what should have meaning). It is also, in this sense, that art must invent the criteria by which it is 'understood', which does not necessarily involve the register of interpretation (to follow Lyotard again, meaning might mean simply that we are 'set in motion' by the work). Every practice, if it is a practice, is its own genre in this sense - and, as such, to say it again, constitutes its own world. But that other place from where art is pitched is also a world, one whose very edges are now revealed by this doubling. Ultimately, an art practice maintains a critical function in this respect insofar as it turns away from that other myth-system which it has revealed as such. Myth-science is a good name for this world-building - and world-breaking - technology.

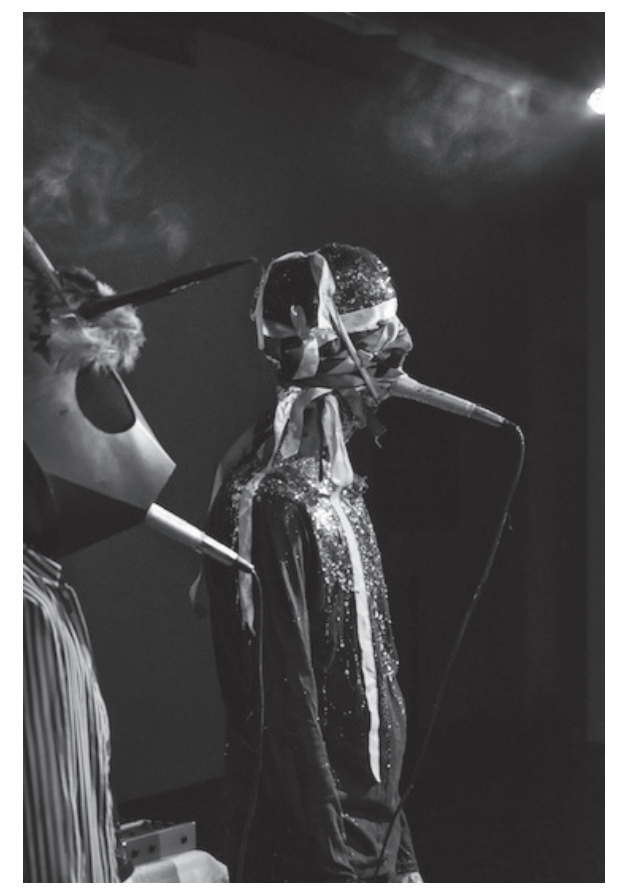




\section{Coda: Guattari and Fabulous Images}

In the section 'Genet Regained' in Schizoanalytic Cartography, Guattari offers another inflection on the relation between fiction and life - or, more especially, the connection of poetics to a politics that is itself understood as the summoning/production of a people. ' In Genet's case, Guattari suggests that there is a 'subterranean process' - a kind of ur-processuality - that characterizes, but that is also prior to, the work and life of the author and that it is this 'ground' that provides a link between the two (a link between the clinical and the critical).

This understanding of an intimate connection between art and life suggests that the former should not be considered simply a representation of the latter, or indeed, be simply defined as a utopian imaging. Although in his own solo work Deleuze uses the term fabulation (a concept borrowed from Henri Bergson), Guattari here suggests that Genet does not so much offer what Guattari calls a 'derealising fabulation', but rather 'fabulous images' (amongst other things) that are involved in a particular 'image function', part of a processual praxis that ultimately opens the reader up to new universes of reference and, consequently, the production of a new subjectivity. ${ }^{8}$ Art is not an inert reflection of the world-as-it-is in this sense, but a kind of subjective technology - a fictioning - involved in the production of a different mode of being in the world.

Guattari writes of Genet's fascination with the Black Panthers as an example of this image function: 'the ways of being and dressing of the Black Panthers, which almost overnight change the way black people as a whole perceive the colour of their skin or the texture of their hair for example' (Guattari 2013, 222). Crucially, Guattari also suggests that:

one can legitimately broaden this expression to all the imaginary formations that, from this same perspective, acquire a particular - transversal - capacity to bridge times of life, existential levels as much as social segments, even - why not - cosmic stratifications. (Guattari 2013, 220)

The image function of art operates as a connector between regimes, a bridge between different existential levels of life. It also offers up a point of inspiration around which a different kind of construction can begin to occur - and, as such, attain

7 And in this sense Guattari's ideas offer a compelling supplement to his and Deleuze's concept of a minor literature which also involves this address to a people-yet-to-come. See especially Chapter 3, "What is a Minor Literature?" in Deleuze/Guattari 1986, 16-27; and, for a discussion of the minor in relation to contemporary art, Chapter 2, "Art and the Political: Minor Literature, the War Machine and the Production of Subjectivity”, of O'Sullivan 2006, 69-97. (Thanks to Theo ReevesEvison for first pointing me towards Guattari's essay on Genet.)

8 Deleuze discusses Bergson's concept of fabulation (or 'story telling') in the last few pages of Bergsonism (Deleuze 1991, 106-112) where it is portrayed as a mechanism that produces an interval within society through which 'creative emotion' might arise. Elsewhere, Deleuze uses the concept of fabulation more specifically in relation to a political project (as bridge between the critical (work) and clinical (author)). See, as indicative, the essay 'Literature and Life', where Deleuze suggests that "It is the task of the fabulating function to invent a people" (Deleuze 1997, 4). 
consistency. Here fiction operates as the friction - the cohering mechanism - for a different subjectivity.

The first stage in this processuality - 'modular crystallization' - involves the production of various images and names that collapse different universes together (including, crucially, a shuttling between signifier and signified, content and expression). Guattari suggests that this is somewhat akin to what Freud writes about in his work on jokes and on dreams. We might say it is the work of condensation.

The second stage involves the production of 'fabulous images' themselves, which enlarge:

fields of virtuality, allowing new Universes of reference and singular modalities of expression to emerge by conjugating heterogeneous voices. In two words, it is a matter of producing another real, correlative to another subjectivity. (Guattari 2013, 225)

These fabulous images - points of condensation that become points of conjunction (achieving, it seems to me, a certain density) - operate as probe-heads, experimental devices that themselves map out a different reality ('another real'), which, as Guattari suggests, is 'correlative to another subjectivity'.

The third and final moment is when these images themselves become 'existential operators' - or synapses - for new kinds of enunciation whose 'function is to produce a singular temporality, a specific way of discursivising subjectivity' (Guattari 2013, 229). This is when art becomes what Guattari calls elsewhere a Z-Point, that operates as a point of cohesion but also (and this relates to some of my previous comments about collapse) as a void point, a line to an Outside. ${ }^{9}$ Guattari writes about a kind of self-fashioning - or 'self divination' - that proceeds from these points (Guattari 2013, 229).

Henceforth, numen no longer affixes itself to the marrow of images, but finds itself distilled in much more molecular praxes, if you will, appropriate for transforming the everyday perception of the world and eschatological horizons. (Guattari 2013, 230)

With this stage the crossing is made from art to life - or, to put this differently, there is a rhythm produced that crosses over the gulf. Art becomes what Foucault might call a technology of the self in so far as it provides a different kind of anchor point for a different practice of living. Indeed, here the poetic function meets the political one and art - as fictioning - announces and helps produce a new subjectivity (alongside a new relation to the Outside) against what William Burroughs, and then Gilles Deleuze, once called Control. ${ }^{10}$

9 I have written at more length about these mutant nuclei and how they cohere subjectivity around themselves in O'Sullivan 2012, 96-103. For more on how these points might also be holes to an Outside, see Burrows/O'Sullivan 2014.

10 See Burroughs 2014 and Deleuze 1995. I go in to more detail about the possible contours and concepts - from a Deleuzian perspective - of an artistic war machine that might be pitched against 


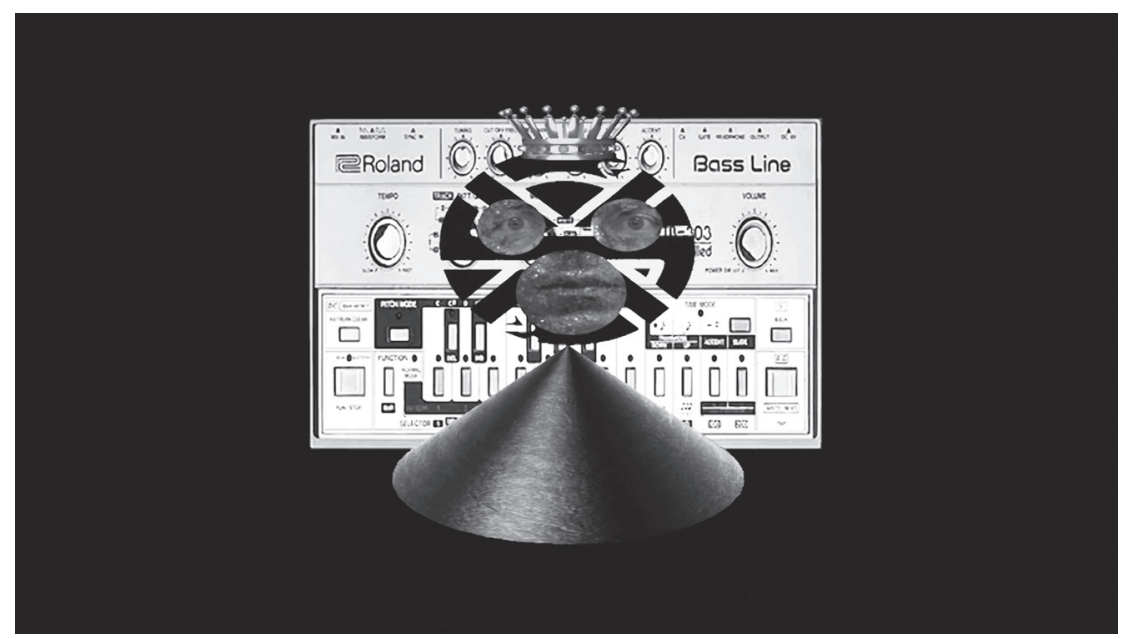

\section{References}

Burroughs, William S. (2014): The Limits of Control. In: Sylvère Lotringer (ed.): Schizo-Culture: The Book. New York: Semiotext(e), 38-43.

Burrows, David/O'Sullivan, Simon (2014): The Sinthome/Z-Point Relation or Art as Non-Schizoanalysis. In: Ian Buchanan/Lorna Collins (eds.): Deleuze and the Schizoanalysis of Visual Art. London: Bloomsbury, 253-278.

Deleuze, Gilles (1989): Cinema 2: The Time-Image. Trans. H. Tomlinson/R. Galeta. Minneapolis: University of Minnesota Press.

Deleuze, Gilles (1991): Bergsonism. Trans. H. Tomlinson/B. Habberjam, New York: Zone Books.

Deleuze, Gilles (1995): Postscript on the Societies of Control. In: Negotiations: 1972-1990. Gilles Deleuze. Trans. M. Joughin. New York: Columbia University Press, 177-182.

Deleuze, Gilles (1997): Literature and Life. In: Essays Critical and Clinical. Trans. D. W. Smith/M. A. Greco. Minneapolis: University of Minnesota Press, 1-6.

Deleuze, Gilles/Guattari, Félix (1984): Anti-Oedipus: Capitalism and Schizophrenia. Trans. R. Hurley/M. Seem/H. R. Lane, London: Athlone Press.

Deleuze, Gilles/Guattari, Félix (1986): Kafka: Towards a Minor Literature. Trans. D. Polan. Minneapolis: University of Minnesota Press.

Deleuze, Gilles/Guattari, Félix (1988): A Thousand Plateaus. Trans. B. Massumi. London: Athlone Press.

Eshun, Kowdo (1998): More Brilliant than the Sun: Adventures in Sonic Fiction. London: Quartet.

Guattari, Félix (2013): Genet Regained. In: Schizoanalytic Cartographies. Trans. A. Goffey. London: Bloomsbury, 215-230.

Control in O'Sullivan 2016a. 
Kelley, Mike (1995): Myth Science. In: Öyvind Fahlstrom: The Installations. Ostfildern: Hatje Cantz, 19-27.

Lyotard, Jean-François (1984): The Postmodern Condition: A Report on Knowledge. Trans. G. Bennington/B. Massumi. Manchester: Manchester University Press.

O'Sullivan, Simon (2006): Art Encounters Deleuze and Guattari: Thought Beyond Representation. Basingstoke: Palgrave Macmillan.

O'Sullivan, Simon (2012): On the Production of Subjectivity: Five Diagrams of the Finite-Infinite Relation. Basingstoke: Palgrave Macmillan.

O’Sullivan, Simon (2014): Art Practice as Fictioning (or, myth-science). In: diakron, no. 1. http://www. diakron.dk (last accessed 19 October 2015).

O’Sullivan, Simon (2016a): Deleuze Against Control: Fictioning to Myth-Science. In: Theory Culture Society. 2 June, 2016. doi: 10.1177/0263276416645154.

O’Sullivan, Simon (2016b): Accelerationism, Prometheanism and Myth-Science. In: Amy Ireland/ Baylee Brits/Prudence Gibson (eds.): Aesthetics After Finitude. Melbourne: re:press, 171-189.

O'Sullivan, Simon (2017): Accelerationism, Hyperstition and Myth-Science. In: Ed Keller/Tim Matts/ Benjamin Noys (eds.): Accelerationism and the Occult. New York: Punctum Books, forthcoming. Williams, Alex (2013): Escape Velocities. In: E-Flux \#46, 1-11. 